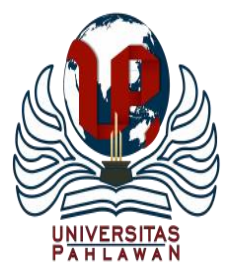

Edukatif : Jurnal Ilmu Pendidikan Volume 3 Nomor 5 Tahun 2021 Halm 2071 - 2078

EDUKATIF: JURNAL ILMU PENDIDIKAN

Research \& Learning in Education

https://edukatif.org/index.php/edukatif/index

\title{
Meningkatkan Hasil Belajar Siswa Pada Mata Pelajaran IPS Melalui Model Pembelajaran Make A Match di Sekolah Dasar
}

\author{
Faslia \\ Pendidikan Guru Sekolah Dasar, Universitas Muhammadiyah Buton \\ E-mail : dra.faslia13@gmail.com
}

\begin{abstract}
Abstrak
Tujuan penelitian ini untuk meningkatkan hasil belajar Ilmu Pengetahuan Sosial (IPS) pada siswa kelas V SD dengan menggunakan model pembelajaran Make A Match. Jenis penelitian ini adalah penelitian tindakan kelas yang terdiri dari 2 siklus. Masing-masing siklus yang diteliti terdiri dari perencanaan, pelaksanaan, observasi, dan refleksi. Hasil penelitian menunjukkan bahwa pada tes awal sebelum melakukan tindakan menunjukkan bahwa siswa yang memperoleh nilai $\geq 65$ berjumlah 6 orang dari 28 siswa dengan presentasi $21,42 \%$ sedangkan siswa yang tidak memperoleh nilai $\leq 65$ berjumlah 22 orang dengan presentasi $78,57 \%$. Pada siklus 1 menunjukkan adalnya peningkatan dimana siswa yang memperoleh nilai $\geq 65$ sebanyak 14 orang siswa atau sebesar 50\% dengan nilai rata-rata 61,96. Siklus 2 juga mengalami peningkatan dari siklus 1 dimana siswa yang memperoleh nilai $\geq 65$ sebanyak 23 orang siswa atau sebesar 82,14 \% dengan nilai rata-rata 72,32. Dari hasil observasi, evaluasi dan refleksi pada setiap tindakan kelas, maka dapat disimpulkan bahwa kemampuan siswa kelas V SD Negeri 6 Kota Baubau dalam menyelesaikan soal-soal ilmu pengetahuan sosial tentang kenampakan alam di Indonesia dapat ditingkatkan melalui pembelajaran Make A Match.
\end{abstract}

Kata Kunci: Hasil Belajar, Metode Pembelajaran, Make A Match.

\section{Abstract}

The purpose of this study was to improve learning outcomes of Social Sciences (IPS) in fifth grade elementary school students by using the Make A Match learning model. This type of research is classroom action research which consists of 2 cycles. Each cycle studied consisted of planning, implementation, observation, and reflection. The results showed that in the initial test before taking action, there were 6 students who scored 65 with a presentation of $21.42 \%$, while students who did not score 65 were 22 with a presentation of $78.57 \%$. In cycle 1, there is an increase where students who get a score of 65 are 14 students or $50 \%$ with an average value of 61.96. Cycle 2 also experienced an increase from cycle 1 where students who scored 65 were 23 students or $82.14 \%$ with an average score of 72.32. From the results of observations, evaluations and reflections on each class action, it can be concluded that the ability of fifth graders at SD Negeri 6 Baubau City in solving social science questions about natural features in Indonesia can be improved through Make A Match learning..

Keywords: Learning Outcomes, Learning Methods, Make A Match.

Copyright (c) 2021 Faslia

$\triangle$ Corresponding author

Email : dra.faslia13@gmail.com

DOI : https://doi.org/10.31004/edukatif.v3i5.740

ISSN 2656-8063 (Media Cetak)

ISSN 2656-8071 (Media Online) 


\section{PENDAHULUAN}

Perkembangan kualitas sumber daya manusia tidak lepas dari perkembangan dan kualitas pendidikan (Syachruroji \& Taufik, 2016). Undang-Undang No. 20 tahun 2003 tentang Sistem Pendidikan Nasional Pasal 1 ayat (1) menjelaskan pendidikan sebagai usaha sadar serta terencana agar terwujud suasana belajar dan proses pembelajaran sehingga peserta didik secara aktif mengembangkan potensi dirinya untuk memiliki kekuatan spiritual keagamaan, pengendalian diri, kepribadian, kecerdasan, akhlak mulia serta keterampilan yang diperlukan dirinya, masyarakat, bangsa dan negara (Wijanarko, 2017). Sekolah dasar merupakan sekolah yang berada pada jenjang paling dasar pada pendidikan formal sehingga saat pelaksanaan pembelajaran di sekolah dasar, guru akan menemukan kondisi yang cukup berbeda dan menantang yang mempunyai berpengaruh besar dalam proses pembelajaran. Ansuhadar menyebut pendidikan sebagai proses pengubahan sikap dan tata laku seseorang atau kelompok dalam usaha mendewasakan manusia melalui upaya pengajaran dan latihan (Isnaeni \& Radia, 2021) .

Dalam Pembelajaran Ilmu Pengetahuan Sosial (IPS) sangat membutuhkan berbagai bentuk komunikasi dengan peserta didik. Proses ini pada dasarnya merupakan proses negoisasi pesan dalam suatu keadaan atau situasi. Mata Pelajaran Ilmu Pengetahuan Sosial di SD mengkaji seperangkat peristiwa, fakta, konsep, dan generalisasi yang berkaitan dengan isu sosial. Pada jenjang SD/MI mata pelajaran Ilmu Pengetahuan Sosial memuat materi Geografi, Sejarah, Sosiologi, dan Ekonomi. Melalui mata pelajaran Ilmu Pengetahuan Sosial, peserta didik diarahkan untuk dapat menjadi warga negara Indonesia yang demokratis, dan bertanggungjawab serta warga dunia yang cinta damai (Ayu Febriana, 2011). Proses belajar mengajar terus terjadi karena peran manusia sehingga pada dasarnya belajar merupakan kegiatan manusia yang terus terjadi sepanjang hayatnya atau paling tidak, dia senantiasa belajar walaupun sudah lulus dari sekolah. Dalam hal ini, belajar dapat berarti sebagai penambahan pengetahuan, baik penambahan dalam ranah kognitif, afektif, maupun psikomotorik (Hanafy, 2014).

Pendidikan IPS adalah penyederhaan adaptasi, seleksi dan modifikasi dari disiplin akademis ilmu sosial yang diorganisasikan dan disajikan secara ilmiah dan pedagogis psikologis untuk tujuan institusional pendidikan dasar dan menengah dalam kerangka mewujudkan tujuan pendidikan nasional yang berdasarkan pancasila (Widodo et al., 2020). Solihatin "pembelajaran Ilmu Pengetahuan Sosial (IPS) lebih menekankan pada aspek "Pendidikan" daripada "Transfer Konsep", karena dalam pembelajaran pendidikan IPS diharapkan memperoleh pemahaman terhadap sejumlah konsep dan mengembangkannya serta melatih nilai, moral, sikap dan keterampilannya atas dasar konsep yang sudah iya dimilikinya"(Ananda, 2019). Ilmu Pengetahuan Sosial merupakan (IPS) merupakan salah satu mata pelajaran yang diberikan di tingkat SD/MI/SDLB. IPS mengkaji seperangkat peristiwa, fakta, konsep dan generalisasi yang berkaitan dengan isu sosial (Nofiaturrahmah, 2015). Ilmu Pengetahuan Sosial adalah program pendidikan yang mengintegrasikan secara interdisiplin konsep ilmu-ilmu sosial dan humaniora (Rahmawati, 2020).

Model pembelajaran adalah pola yang digunakan sebagai pedoman dalam merencanakan pembelajaran di kelompok maupun tutorial (Suprijono, 2010). Rusman menjelaskan model pembelajaran sebagai pola pilihan, artinya para guru diperbolehkan memilih model pembelajaran yang sesuai dan efisien untuk mencapai tujuan pendidikannya (Wijanarko, 2017). Model pembelajaran Make a Match adalah salah satu model pembelajaran yang berorientasi pada permainan. Menurut Suyatno prinsip-prinsip model make a match antara lain: (1) Anak belajar melalui berbuat, (2) Anak belajar melalui panca indera, (3) Anak belajar melalui bahasa, dan (4) Anak belajar melalui bergerak ("Pengaruh Model Pembelajaran Make A Match Dalam Peningkatan Pemahaman Siswa Tentang Tokoh Pejuang Melawan Penjajah Belanda Di Kelas V SD,” 2018). Model pembelajaran adalah kulit atau bingkai dari penerapan suatu konsep pendekatan, teknik, dan model pembelajaran. Fungsi model dalam pembelajaran merupakan panduan dalam merancang pembelajaran para guru untuk melaksanaakan proses pembelajaran (Trianto, 2010: 51). 


\section{Meningkatkan Hasil Belajar Siswa Pada Mata Pelajaran IPS Melalui Model Pembelajaran Make A Match di Sekolah Dasar - Faslia}

DOI: https://doi.org/10.31004/edukatif.v3i5.740

Metode Make A Match penerapanya dimulai dengan siswa yang disuruh mencocokan pasangan kartu yang terdiri satu kartu soal dan satu kartu jawaban sebelum batas waktunya, sehingga siswa yang sudah/dapat menemukan pasangan kartunya akan diberikan skor penilaian. Secara rinci langkah dalam pembelajaran Make a Match adalah sebagai berikut : (1) Guru menyiapkan beberapa kartu yang berisi beberapa konsep atau topik yang cocok untuk sesi review, satu bagian kartu soal dan bagian lainnya kartu jawaban. (2) Setiap peserta didik mendapat satu kartu. (3) Kartu soal yang pegang akan diberikan beberapa waktu untuk dipikirkan jawabanya. (4) Setiap peserta didik mencari pasangan yang mempunyai kartu yang cocok dengan kartunya (soal jawaban). Setelah persoalan dipecahkan, peserta didikan saling mencari pasangan. (5) Setiap peserta didik yang dapat mencocokkan kartunya sebelum batas waktu diberi poin. (6) Setelah satu babak kartu maka kartu kembali dikocok kembali sehingga peserta didik mengambil kartu yang jenisnya beda dengan yang sebelumnya. (7) Demikian seterusnya, lakukan secara berulang sampai waktu pembelajaran selesai. (8) Kesimpulan/penutup . Setelah selesai buatlah kesimpulan secara bersama-sama.

Djumiati menjelaskan bahwa; (1) model pembelajaran kooperatif tipe Make A Match bertujuan untuk menumbuhkan sikap saling menghormati, menumbuhkan sikap tanggungjawab, meningkatkan percaya diri dalam menyelesaikan suatu masalah, (2) merupakan model pembelajaran yang menuntut anak didik aktif dalam pembelajaran, keterampilan keterampilan mulai dari tingkat awal maupun tingkat mahir yang dimiliki anak didik akan terlihat dalam pembelajaran ini, (3) lingkungan dalam pembelajaran Make A Match diusahakan demokratis, anak didik diberi kebebasan untuk mengutarakan pendapat (Aliputri, 2018).

Benny menjelaskan aturan permainan yaitu sebelum guru menerapkan model Make a Match terlebih dahulu mempertimbangkan: (1) kondisi kelas yang meliputi jumlah siswa dan efektifitas ruangan (2) indikator yang ingin dicapai (3) waktu yang tersedia untuk digunakan dan waktu yang dipersiapan. Persiapan yang perlu dilakukan apabila pembelajaran menggunakan Make A Match dengan pengembangan yaitu kartu-kartu (Anggarawati et al., 2014).

Istarani menjelaskan bahwa model pembelajaran make a match memiliki kelebihan dan kelemahan. Kelebihan dari model ini adalah; (1) dapat menumbuhkan kreativitas berfikir siswa, sebab melalui pencocokkan pertanyaan dan jawaban akan tumbuh tersendirinya, (2) pembelajaran lebih menyenangkan karena melibatkan media pembelajaran yang digunakan guru, (3) siswa terlibat langsung dalam menjawab soal yang disampaikan kepadanya melalui kartu, (4) meningkatkan kreativitas belajar siswa, (5) menghindari kejenuhan siswa dalam mengikuti proses belajar mengajar. Sedangkan kelemahan dari model ini, yaitu ; (1) sulit mengatur ritme atau jalannya proses pembelajaran, (2) sulit bagi guru mempersiapkan kartu-kartu yang baik dan bagus, (3), sulit untuk mengkonsentrasikan anak (4) siswa kurang memahami makna pembelajaran yang ingin disampaikan karena merasa hanya sekedar permainan saja (Makmur Sirait \& Noer, 2013).

Pada hasil analisis data observasi awal, menunjukkan bahwa hasil belajar siswa SD Negeri 6 Baubau khususnya mata pelajaran Ilmu Pengetahuan Sosial masih belum optimal mengingat hasil yang menunjukkan ketuntasan belajar siswa yang masih di bawah KKM, sehingga peneliti menduga adanya kelemahan dalam penerapan metode pembelajaran di SD Negeri 6 Kota Baubau yang perlu dilakukan sebuah penerapan metode yang dianggap efektif dalam penerapan pada mata pelajaran Ilmu Pengetahuan Sosial.

Metode Make a Match merupakan metode yang sudah banyak diteliti. Salah satunya adalah penelitian dari Ayu Febriani pada jurnal Kreatif Jurnal Kependidikan Dasar yang secara spesifik mengkaji objek yang sama dalam penelitian ini. Namun pada penelitian dengan judul Penerapan Model Pembelajaran Kooperatif Tipe Make A Match untuk Meningkatkan Kualitas Pembelajaran IPS Siswa Kelas V SDN Kalibanteng Kidul 01 Kota Semarang tidak secara spesifik mengkaji peningkatan hasil belajar siswa, sehingga pada penelitian ini kebaruan yang peneliti ajukan adalah penggunaan model dengan spesifik pada pengukuran peningkatan hasil belajar, dan pada materi yang lebih spesifik yakni tentang Tentang Kenampakan Alam di Indonesia. 

di Sekolah Dasar - Faslia

DOI: https://doi.org/10.31004/edukatif.v3i5.740

\section{METODE PENELITIAN}

Rancangan penelitian yang penulis lakukan menggunakan desain Penelitian Tindakan Kelas (PTK). Penelitian tindakan kelas adalah penelitian yang dilakukan oleh guru di kelasnya sendiri melalui refleksi diri dengan tujuan untuk memperbaiki kinerjanya sehingga hasil belajar siswa meningkat (Aqib \& Amrullah, 2018). Objek penelitian ini adalah metode Make a Match dengan subjek siswa kelas V SD Negeri 6 Kota Baubau. Pada penerapan metode ini terdiri dari perencanaan, tindakan, observasi dan refleksi.

Data penelitian ini terdiri dari data primer dan data sekunder. Data primer merupakan data yang bersumber dari Guru Kelas V SD Negeri 6 Kota Baubau dan data hasil belajar siswa setelah melakukan tindakan, sedangkan data sekunder merupakan data yang bersumber dari tinjauan literatur yang relefan dengan penelitian ini.

Pengolahan data pada penelitian ini dengan menganalisis data hasil peneliti yang terkumpul untuk segera diolah. Data dari hasil pengamatan diolah dengan analisis deskriptif untuk menggambarkan keadaan peningkatan pencapaian indikator keberhasilan tiap siklus dan untuk menggambarkan keberhasilan metode Make a Match yang dapat meningkatkan hasil belajar siswa (Arikunto, 2002).

Rumus menghitung nilai presentase siswa adalah sebagai berikut (Indarwati et al., 2014):

$$
\mathrm{P}=\frac{\text { Siswa yang tuntas belajarnya }}{\text { Seluruh siswa }} \times 100 \%
$$

\section{HASIL DAN PEMBAHASAN PENELITIAN}

Penelitian ini menerapkan metode Make a Match dalam rangka meningkatkan hasil belajar siswa kelas V SD Kota Baubau dengan materi tentang kenampakan alam di Indonesia. Berdasarkan hasil tes awal tersebut, mengungkapkan bahwa siswa SD Negeri 6 Baubau kelas V yang memperoleh nilai $\geq 65$ berjumlah 6 orang dari 28 siswa dengan presentasi $21,42 \%$ sedangkan siswa yang tidak memperoleh nilai $\leq 65$ berjumlah 22 orang dengan presentasi $78,57 \%$. Hal ini memberi gambaran bahwa hasil belajar ilmu pengetahuan sosial siswa pada kelas tersebut masih rendah.

Tabel 1. Perolehan Nilai Pada Tes Awal

\begin{tabular}{cll}
\hline No. & \multicolumn{1}{c}{ Nama Siswa } & Nilai \\
\hline $\mathbf{1}$ & Akram & 65 \\
\hline $\mathbf{2}$ & Fatul Rahmat & 70 \\
\hline $\mathbf{3}$ & L.M Zakir Al-Muharam & 40 \\
\hline $\mathbf{4}$ & M.Fahrianto & 30 \\
\hline $\mathbf{5}$ & Muh.Herzaidin Gusman & 75 \\
\hline $\mathbf{6}$ & Nasrul & 20 \\
\hline $\mathbf{7}$ & Wahyu & 45 \\
\hline $\mathbf{8}$ & Agustina & 50 \\
\hline $\mathbf{9}$ & Lulu Afiyanto & 50 \\
\hline $\mathbf{1 0}$ & Melisa Salsabilah & 40 \\
\hline $\mathbf{1 1}$ & Najla Nuraini.A & 70 \\
\hline $\mathbf{1 2}$ & Nurlin & 65 \\
\hline $\mathbf{1 3}$ & Reva April Yani.R & 70 \\
\hline $\mathbf{1 4}$ & Siti Rabiah Hasim & 20 \\
\hline $\mathbf{1 5}$ & Waode Musrifa & 40 \\
\hline $\mathbf{1 6}$ & Yusrina & 30 \\
\hline $\mathbf{1 7}$ & Adit & 50 \\
\hline $\mathbf{1 8}$ & Inda Ayu Putri Julianti & 60 \\
\hline
\end{tabular}


2075 Meningkatkan Hasil Belajar Siswa Pada Mata Pelajaran IPS Melalui Model Pembelajaran Make A Match di Sekolah Dasar - Faslia

DOI: https://doi.org/10.31004/edukatif.v3i5.740

\begin{tabular}{llc}
\hline $\mathbf{1 9}$ & Herdian Safitra & 45 \\
\hline $\mathbf{2 0}$ & Sharil & 50 \\
$\mathbf{2 1}$ & Selfianti & 70 \\
\hline $\mathbf{2 2}$ & Rahmat & 20 \\
\hline $\mathbf{2 3}$ & Riska & 40 \\
\hline $\mathbf{2 4}$ & Putri & 50 \\
\hline $\mathbf{2 5}$ & Yatri & 60 \\
\hline $\mathbf{2 6}$ & Yusuf & 50 \\
\hline $\mathbf{2 7}$ & Ledy Atu Fortuna & 40 \\
\hline $\mathbf{2 8}$ & Zulfikar & 20 \\
\hline & Rata-rata & $\mathbf{4 7 , 8 5}$ \\
\hline & Nilai $\geq \mathbf{6 5}$ & $\mathbf{6}$ orang \\
\hline \multicolumn{2}{c}{ Nilai Ketuntasan (\%) } & $\mathbf{2 1 , 4 2} \%$ \\
\hline \multicolumn{2}{c}{ Sumber data $:$ Hasil Belajar Siswa $\mathbf{2 0 2 1}$}
\end{tabular}

Berdasarkan hasil tes awal hasil belajar siswa masih rendah karena guru masih menerapkan pembelajaran konvensional atau transformasi pengetahuan terpusat pada guru, dimana guru jarang menerapkan belajar kelompok dan cara kerja kelompok yang tidak terstruktur.

Pada siklus 1 Hasil tes menunjukkan bahwa kemampuan siswa dalam menyelesaikan soal-soal mengalami peningkatan. Pada tes awal, siswa yang memperoleh nilai $\geq 65$ sekitar 21,42\% atau sebanyak 6 orang dengan nilai rata-rata 47,85 . Sedangkan hasil tes tindakan siklus I dapat dilihat pada tabel di bawa ini

Tabel. 2 Perolehan Nilai Pada Tes Tindakan Siklus I

\begin{tabular}{cll}
\hline No. & \multicolumn{1}{c}{ Nama Siswa } & Nilai \\
\hline $\mathbf{1}$ & Akram & 70 \\
\hline $\mathbf{2}$ & Fathul Rahmat & 75 \\
\hline $\mathbf{3}$ & L.M. Zakir Al-Muharam & 55 \\
\hline $\mathbf{4}$ & M.Fahrianto & 50 \\
\hline $\mathbf{5}$ & Muh.Herzaidin Gusman & 80 \\
\hline $\mathbf{6}$ & Nasrul & 40 \\
\hline $\mathbf{7}$ & Wahyu & 55 \\
\hline $\mathbf{8}$ & Agustina & 65 \\
\hline $\mathbf{9}$ & Lulu Afiyanto & 70 \\
\hline $\mathbf{1 0}$ & Melisa Salsabila & 55 \\
\hline $\mathbf{1 1}$ & Najla Nuraini & 75 \\
\hline $\mathbf{1 2}$ & Nurlin & 70 \\
\hline $\mathbf{1 3}$ & Reva April Yani.R & 85 \\
\hline $\mathbf{1 4}$ & Siti Rabiah Hasim & 45 \\
\hline $\mathbf{1 5}$ & Waode Musrifa & 50 \\
\hline $\mathbf{1 6}$ & Yusrina & 50 \\
\hline $\mathbf{1 7}$ & Adit & 65 \\
\hline $\mathbf{1 8}$ & Inda Ayu Putri Julianti & 75 \\
\hline $\mathbf{1 9}$ & Herdian Safitri & 60 \\
\hline $\mathbf{2 0}$ & Sharil & 60 \\
\hline $\mathbf{2 1}$ & Selfianti & 75 \\
\hline $\mathbf{2 2}$ & Rahmat & 50 \\
\hline $\mathbf{2 3}$ & Riska & 65 \\
\hline $\mathbf{2 4}$ & Putri & 60 \\
\hline $\mathbf{2 5}$ & Yatri & 70 \\
\hline & &
\end{tabular}


2076 Meningkatkan Hasil Belajar Siswa Pada Mata Pelajaran IPS Melalui Model Pembelajaran Make A Match di Sekolah Dasar - Faslia

DOI: https://doi.org/10.31004/edukatif.v3i5.740

\begin{tabular}{llc}
\hline $\mathbf{2 6}$ & Yusuf & 50 \\
\hline $\mathbf{2 7}$ & Ledy Atu Fortuna & 65 \\
\hline $\mathbf{2 8}$ & Zulfikar & 50 \\
\hline & Rata-rata & $\mathbf{6 1 , 9 6}$ \\
\hline & Nilai $\geq \mathbf{6 5}$ & $\mathbf{1 4}$ orang \\
\hline \multicolumn{2}{c}{ Nilai Ketuntasan (\%) } & $\mathbf{5 0} \%$ \\
\hline \multicolumn{2}{c}{ Sumber data : Hasil Belajar Siswa $\mathbf{2 0 2 1}$} \\
\end{tabular}

Berdasarkan hasil evaluasi yang dilakukan pada siklus II, siswa yang memperoleh nilai $\geq 65$ sebanyak 23 orang siswa atau sebesar $82,14 \%$ dengan nilai rata-rata 72,32. Adapun nilai keseluruhan siswa pada siklus II dapat di lihat pada tabel di bawah ini:

Tabel 3. Perolehan Nilai Pada Tes Tindakan Siklus II

\begin{tabular}{clc}
\hline No. & \multicolumn{1}{c}{ Nama Siswa } & Nilai \\
\hline $\mathbf{1}$ & Akram & 85 \\
\hline $\mathbf{2}$ & Fathul Rahmat & 80 \\
\hline $\mathbf{3}$ & L.M Zakir Al-Muharam & 65 \\
\hline $\mathbf{4}$ & M.Fahriyanto & 60 \\
\hline $\mathbf{5}$ & Muh.Herzaidin Gusman & 90 \\
\hline $\mathbf{6}$ & Nasrul & 50 \\
\hline $\mathbf{7}$ & Wahyu & 60 \\
\hline $\mathbf{8}$ & Agustina & 75 \\
\hline $\mathbf{9}$ & Lulu Afiyanto & 80 \\
\hline $\mathbf{1 0}$ & Melisa Salsabila & 60 \\
\hline $\mathbf{1 1}$ & Najla Nuraini & 80 \\
\hline $\mathbf{1 2}$ & Nurlin & 75 \\
\hline $\mathbf{1 3}$ & Reva April Yani & 90 \\
\hline $\mathbf{1 4}$ & Siti Rabiah Hasim & 60 \\
\hline $\mathbf{1 5}$ & Waode Musrifa & 65 \\
\hline $\mathbf{1 6}$ & Yusrina & 70 \\
\hline $\mathbf{1 7}$ & Adit & 70 \\
\hline $\mathbf{1 8}$ & Inda Ayu Putri Julianti & 80 \\
\hline $\mathbf{1 9}$ & Herdian Safitra & 75 \\
\hline $\mathbf{2 0}$ & Sharil & 75 \\
\hline $\mathbf{2 1}$ & Selfiyanti & 80 \\
\hline $\mathbf{2 2}$ & Rahmat & 70 \\
\hline $\mathbf{2 3}$ & Riska & 75 \\
\hline $\mathbf{2 4}$ & Putri & 75 \\
\hline $\mathbf{2 5}$ & Yatri & 70 \\
\hline $\mathbf{2 6}$ & Yusuf Umbu & 80 \\
\hline $\mathbf{2 7}$ & Ledy Atu Fortuna & 70 \\
\hline $\mathbf{2 8}$ & Zulfikar & $\mathbf{7 2 , 3 2}$ \\
\hline & Rata-rata & $\mathbf{2 3}$ orang \\
\hline & Nilai $\geq \mathbf{6 5}$ & $\mathbf{8 2 , 1 4 \%}$ \\
\hline & Nilai Ketuntasan (\%) & $\mathbf{2 0 2 1}$ \\
\hline & & \\
\hline & & Sumber data $\mathbf{\text { Hasil Belajar Siswa }}$ \\
\hline
\end{tabular}


Karena indikator keberhasilan dalam penelitian ini telah tercapai, dalam hal ini minimal $80 \%$ siswa telah mencapai nilai $\geq 65$, maka penelitian dihentikan pada siklus II. Ini berarti bahwa hipotesis tindakan telah tercapai yaitu melalui pembelajaran Make A Match dalam proses belajar mengajar, maka kemampuan siswa kelas V SD Negeri 6 Baubau dalam menyelesaikan soal-soal ilmu pengetahuan sosial tentang kenampakan alam dapat ditingkatkan.

Hasil penelitian menunjukkan bahwa pada tes awal sebelum melakukan tindakan menunjukkan bahwa siswa yang memperoleh nilai $\geq 65$ berjumlah 6 orang dari 28 siswa dengan presentasi 21,42\% sedangkan siswa yang tidak memperoleh nilai $\leq 65$ berjumlah 22 orang dengan presentasi 78,57\%. Pada siklus 1 menunjukkan adalnya peningkatan dimana siswa yang memperoleh nilai $\geq 65$ sebanyak 14 orang siswa atau sebesar 50\% dengan nilai rata-rata 61,96. Siklus 2 juga mengalami peningkatan dari siklus 1 dimana siswa yang memperoleh nilai $\geq 65$ sebanyak 23 orang siswa atau sebesar 82,14 \% dengan nilai rata-rata 72,32 . Data ini menunjukkan bahwa penggunaan metode Make A Match dapat meningkatkan hasil belajar siswa kelas $\mathrm{V}$ SD Negeri 6 Kota Baubau.

Data tersebut menunjukkan bahwa hasil belajar dengan menggunakan metode Make A Match dapat meningkatkan hasil belajar siswa mata pelajaran Ilmu Pengetahuan Sosial. Hal ini dapat disimpulkan bahwa metode ini bisa diterapkan pada mata pelajaran yang spesifik di bidang eksakta maupun pada pelajaran bidang non eksakta seperti pada objek kajian dalam penelitian ini yakni Mata Pelajaran Ilmu Pengetahuan Sosial dan juga semakin memperuat hasil penelitian Ayu Febriani pada jurnal Kreatif Jurnal Kependidikan Dasar yang menjelaskan adanya peningkatan hasil belajar Ilmu Pengetahuan Sosial dengan penggunaan metode Make a Match.

\section{KESIMPULAN}

Dari hasil observasi awal yang menunjukkan rendahnya hasil belajar siswa yang disebabkan kurangnya antusias siswa dalam mengikuti pelajaran, sehingga dilakukan dengan menggunakan sebuah model yang dimungkinkan siswa berperan aktif dalam proses pembelajaran dengan menerapkan metode Make A Match dapat meningkatkan hasil belajar IPS dengan menerapkan dua kali tindakan yakni pada siklus 1 dan siklus 2 . Data pada hasil pembahasan menunjukkan grafik yang meningkat dari observasi sebelum menerapkan model, sampai pada penerepan model pada siklus pertama dan siklus kedua.

\section{UCAPAN TERIMA KASIH}

Ucapan terimakasih kepada Rektor Universitas Muhammadiyah Buton yang telah mendukung kelancaran penelitian hingga artikel ini dan dapat terbit. Kepada berbagai pihak yang sudah berkontribusi dalam penyelesaian artikel penelitian ini.

\section{DAFTAR PUSTAKA}

Aliputri, D. H. (2018). Penerapan Model Pembelajaran Kooperatif Tipe Make A Match Berbantuan Kartu Bergambar Untuk Meningkatkan Hasil Belajar Siswa. Jurnal Bidang Pendidikan Dasar. Https://Doi.Org/10.21067/Jbpd.V2i1a.2351

Ananda, R. (2019). Penerapan Metode Mind Mapping Untuk Meningkatkan Kemampuan Berpikir Kreatif Siswa Sekolah Dasar. Edukatif: Jurnal Ilmu Pendidikan. Https://Doi.Org/10.31004/Edukatif.V1i1.1

Anggarawati, A., Kristiantari, R., \& Asri, A. S. (2014). Pengaruh Make A Match Berbantuan Media Kartu Gambar Terhadap Hasil Belajar IPA SD. Jurnal Mimbar PGSD Universitas Pendidikan Ganesha.

Aqib, Z., \& Amrullah, A. (2018). Ptk Penelitian Tindakan Kelas Teori Dan Aplikasinya. Ptk Penelitian 
2078 Meningkatkan Hasil Belajar Siswa Pada Mata Pelajaran IPS Melalui Model Pembelajaran Make A Match di Sekolah Dasar - Faslia

DOI: https://doi.org/10.31004/edukatif.v3i5.740

Tindakan Kelas Teori Dan Aplikasinya.

Arikunto, S. (2002). Metodologi Penelitian Suatu Pendekatan Proposal. 2017.

Ayu Febriana. (2011). ( Application Of Cooperative Learning Model Type Make A Ayu Febriana Teacher At Primary School Kalibantengkidul 1, Semarang Abstract. Jurnal Kependidikan Dasar.

Hanafy, M. S. (2014). Konsep Belajar Dan Pembelajaran. Lentera Pendidikan: Jurnal Ilmu Tarbiyah Dan Keguruan. Https://Doi.Org/10.24252/Lp.2014v17n1a5

Indarwati, D., Wahyudi, W., \& Ratu, N. (2014). Peningkatan Kemampuan Pemecahan Masalah Matematika Melalui Penerapan Problem Based Learning Untuk Siswa Kelas V Sd. Satya Widya. Https://Doi.Org/10.24246/J.Sw.2014.V30.I1.P17-27

Isnaeni, R., \& Radia, E. H. (2021). Meta-Analisis Pengaruh Penggunaan Media Audio Visual Terhadap Hasil Belajar IPS Siswa Di Sekolah Dasar. Edukatif: Jurnal Ilmu Pendidikan. Https://Doi.Org/10.31004/Edukatif.V3i2.281

Makmur Sirait, P. A. N., \& Noer, Putri Adilah. (2013). Pengaruh Model Pembelajaran Kooperatif Tipe Make A Match Terhadap Hasil Belajar Siswa Makmur. Pengaruh Model Pembelajaran Kooperatif Tipemake A Match Terhadap Hasil Belajar Siswa.

Nofiaturrahmah, F. (2015). Pelajaran Ilmu Pengetahuan Sosial Untuk Mi Yang Menyenangkan. Elementary.

Pengaruh Model Pembelajaran Make A Match Dalam Peningkatan Pemahaman Siswa Tentang Tokoh Pejuang Melawan Penjajah Belanda Di Kelas V SD. (2018). Pedadidaktika: Jurnal Ilmiah Pendidikan Guru Sekolah Dasar.

Rahmawati, T. N. (2020). Peluang Mata Pelajaran Ilmu Pengetahuan Sosial (IPS) Dalam Mewujudkan Pendidikan Yang Berbasis Multikultural. Jurnal Soshum Insentif. Https://Doi.Org/10.36787/Jsi.V3i1.225

Suprijono, A. (2010). Cooperative Learning Teori Dan Paikem. In Kumpulan Metode Pembelajaran.

Syachruroji, A., \& Taufik, M. (2016). Perbedaan Hasil Belajar Siswa Pada Mata Pelajaran Ilmu Pengetahuan Alam Antara Model Problem Based Learning Dengan Model Pembelajaran Langsung. Jpsd.

Widodo, A., Indraswati, D., Sutisna, D., Nursaptini, N., \& Anar, A. P. (2020). Pendidikan IPS Menjawab Tantangan Abad 21: Sebuah Kritik Atas Praktik Pembelajaran IPS Di Sekolah Dasar. ENTITA: Jurnal Pendidikan Ilmu Pengetahuan Sosial Dan Ilmu-Ilmu Sosial. Https://Doi.Org/10.19105/Ejpis.V2i2.3868

Wijanarko, Y. (2017). Model Pembelajaran Make A Match Untuk Pembelajaran Ipa Yang Menyenangkan. Taman Cendekia: Jurnal Pendidikan Ke-SD-An. Https://Doi.Org/10.30738/Tc.V1i1.1579 